Rev. Sàude públ., S. Paulo

1(2) :210-216, dez. 1967

\title{
PROVA DE HEMAGLUTINAÇÃO PASSIVA PARA A EVIDENCIAÇÃO DA TOXINA DO C. DIPHTHERIAE NA LESÃO DIFTÉRICA (1)
}

Dacio de Almeida CHRISTOVÃO

Luís G. COTILLO Z.

José Alberto Neves CANDEIAS

Foi demonstrada a presença da toxina do $C$. diphtheriae, através de prova de hemaglutinação passiva, usando-se hemácias sensibilizadas com antitoxina diftérica, na lesão da garganta de $47,7 \%$ dos casos suspeitos de difteria examinados no presente trabalho. De $53,0 \%$ dos mesmos pacientes pôde ser isolado bacilo diftérico toxigeno. A prova de hemagiutinação passiva foi a única positiva em $13,6 \%$ dos casos e a cultura, a única positiva em $18,9 \%$. Em 42 criancas normais ou portadoras de faringite ou amigdalite sem nenhuma característica clinica de difteria, a prova de hemaglutinaşão passiva foi negativa. O processo descrito, de execução muito simples, pode acusar o resultado em menos de 2 horas e oferece grande possibilidade de aplicação vantajosa no diagnóstico da difteria.

I N T R O U C A O

O diagnóstico clínico da difteria muitas vêzes é feito sob reserva, dadas as possibilidades conhecidas de outras infecções poderem apresentar lesões semelhantes. Outras vêzes deixa de ser estabelecido pela ocorrência de casos atípicos. De qualquer forma, requer sempre a comprovação de laboratório, pelo menos do ponto de vista da Saúde Pública.

O diagnóstico bacteriológico desta infecção é realizado clàssicamente através do isolamento do $C$. diphtheriae a partir do material colhido da lesão. É processo demorado, podendo o seu resultado exigir até 6 dias, além de estar sujeito a falhas.

Através de reação de hemaglutinação passiva em que se utilizaram de hemácias às quais haviam adsorvido antitoxina diftérica, Christovão \& Cotilloo $^{3}$ (1966) puderam evidenciar e dosar a toxina $C$. diphtheriae no sangue e na urina de doentes de difteria. Julgaram o processo simples, rápido, sensivel e de utilidade no diagnóstico desta infecção.

A toxina diftérica também pode "ser demonstrada na saliva de doentes de difteria (TASman et alii ${ }^{5}, 1954$ ). Empregando-se o método da hemaglutinação passiva acima referido, dada a alta sensibilidade das reações desta natureza, deveria ser possível revelar-se a presença da toxina naquêle substrato em frequêencia maior do que se utilizando de provas intradérmicas em coelho ou de reações de precipitação ou mesmo de difusão em gel. Pareceu, no entanto, aos autores da presente investigação que a pesquisa da toxina na própria lesão, através daquêle processo,

Recebido para publicação em 8-11-1967.

(1) Da Cadeira de Microbiologia Aplicada da Faculdade de Higiene e Saúde Pública da USP. Os resultados preliminares desta investigação foram apresentados, em nota prèvia, na sessão ordinária de 4 de outubro de 1965 do Departamento de Higiene e Medicina Tropical da Associação Paulista de Medicina. 
Christovao, D. de A.; Cotillio Z., L. G. \& CANDEIAS, J. A. N. - Prova de hemaglutinação passíva para a evidenciaça da., Rev. Saúde públ., S. Paulo 1(2): 210-216,. dez. 1967.

poderia ser alternativa de maior probabilidade de sucesso. Se positiva em elevada percentagem de casos, constituiria esta pesquisa outro processq de diagnóstico da difteria, ainda mais simples e mais rápido que a evidenciação da toxina no sangue dos doentes.

\section{MATERIAL E METODOS}

Casos suspeitos de difteria - Os resultados ora apresentados referem-se a doentes internados em 1965 e 1966 no Hospital Emílio Ribas, hospital de doenças infecciosas do Departamento de Saúde, na cidade de Sáo Paulo. Tratava-se sòmente de pacientes com diagnóstico clínico inicial de difteria típica ou de suspeita de difteria. Para muitos, posteriormente, o diagnóstico clínico inicial foi modificado para o de amigdalite aguda não diftérica.

De todos, antes da aplicação de sồo antidiftérico, foi colhido, pelas enfermeiras do hospital, material da lesão da garganta, pela técnica usual, através de chumaço de algodão enrolado na extremidade de fio de arame.

Grupos contrôles - Foram tomados como cuntrôles dois grupos de crianças. 0 primeiro era formado por 31 meninas, internadas em instituição infantil, tôdas com garganta normal ao exame clínico. 0 segundo era de 11 crianças de ambos os sexós que procuraram assistência médica no Centro de Saúde da Faculdade de Higiene e Saúde Pública devido a "dôr de garganta" e que foram diagnosticadas clìnicamente como portadoras de amigdalite ou de amigdalite e faringite de etiologia não diftérica

Destas 42 crianças também se colheu material de garganta pela mesma técnica usada para os doentes clinicamente suspeitos de difteria.

Preparo do material - Recebidas as zaragatoas, cada uma delas era colocada em tubo onde o chumaço de algodão ficava mergulhado em $2,5 \mathrm{ml}$ de solução sa- lina tamponada fosfatada, de pH 7,2. Os tubos eram submetidos a agitação violenta e deixados em repouso durante 3.5 minutos. Em seguida os chumaços eram novamente agitados, ainda dentro da salina tamponada, e retirados, tendo-se o cuidado de espremê-los, fortemente, de encontro às paredes de tubo. A suspensão assim obtida era centrifugada a 3.000 r.p.m. durante 15 minutos e o sobrenadante, constituindo o extrato onde se pesquisaria a presença de toxina diftérica, era transferido, através de pipeta, a outro tubo.

0 sedimento destinava-se ao exame bacteriológico de pesquisa do $C$. diphtheriae.

Exame bacteriológico - A pesquisa da presença do bacilo diftérico foi feita da maneira usual, através da inoculação inicial do sedimento em tubo de meio de Pai e em placa de agar-telurito. Após a incubação de cêrca de 24 horas, as culturas eram examinadas. Das culturas em meio de Pai, verificada a presença de bacilos morfològicamente semelhantes ao bacilo diftérico, passava-se material a placa do meio de isolamento.

Quer das placas primárias ou das secundárias, após 24,48 ou 72 horas de incubação, colônias com características das de $C$. diphtheriae eram pescadas e transferidas a novos tubos de meio de Pai, de onde, após a devida incubação, as culturas isoladas eram repicadas a tubos de fermentação de glicose, sacarose, dextrina e glicerina (Christovão ${ }^{1,2}$, 1957).

Tôdas as cepas morfològicamente semelhantes a bacilo diftérico foram submetidas a pesquisa de toxigenicidade, através das provas "in vivo" $\mathrm{e}$ "in vitro", da inoculação intradérmica em coelho e da difusão em gel. (FroBisher et alii ${ }^{4} 1963$ ).

Pesquisa da toxina diftérica - Nos extratos, obtidos a partir dos chumaços de algodão, foi pesquisada a presença da toxina diftérica através da prova de hemaglutinação passiva empregando-se exatamente a técnica descrita anteriormente 
CHRistovao, D. de A.; Cotillo Z., L. G. \& CANDEIAs, J. A. N. - Prova de hemaglutinação passiva para a evidenciação đa. Rev. Saúde públ., S. Paulo 1(2): 210-216, dez. 1967.

(Christovão \& Cotillo $\left.^{3}, 1966\right)$. Para cada extrato, a prova foi realizada na concentração original e nas diluiçōes, de fator 2 , até $1 / 512$. Sòmente foram considerados positivos os extratos que apresentaram aglutinação pelo menos na diluição $1 / 2$.

\section{R E S ULT A DOS}

Grupos contrôles - Os resultados da pesquisa de toxina diftérica, pela prova de hemaglutinação passiva, no material de garganta das 42 crianças dos grupos contrôles foram todos negativos, quer para as 31 meninas com garganta normal, quer para as 11 crianças portadoras de amigdalite ou de amigdalite e faringite. Para 6 destas, a cultura bacteriológica revelou a presença de estreptococcos hemolíticos e de 5, isolou-se Staphylococcus aureus. No grupo das 31 meninas com garganta normal a cultura bacteriológica foi negativa para bactérias patogênicas, exceto de 1 caso do qual foi isolado $C$. diphtheriae.

Casos supeitos de difteria - Na Tabela encontram-se os resultados referentes a 148 pacientes internados na Enfermaria de Difteria do Hospital Emílio Ribas por suspeita inicial de difteria, dos quais 132 com diagnóstico clínico final de difteria e 16, de amigdalite aguda não diftérica.

a) Casos clinicos de difteria - Dos 132 casos clínicos de difteria, $63(47,7 \%)$ foram positivos pela prova de hemaglutinação passiva e de $70(53,0 \%)$ isolou-se C. diphtheriae toxígeno.

Tomando-se os casos positivos revelados por ambas as técnicas ou apenas por. uma delas, encontram-se $88(67,7 \%)$. Dêstes, a prova de hemaglutinação passiva evidenciou $71,6 \%$ e a cultura, $79,5 \%$.

Ambos os processos acusam resultado igual em 45 casos positivos $(34,1 \%)$ e em 44 negativos $(33,3 \%)$. Mostraram-se concordantes, portanto, em 89 casos $(67,4 \%)$. Considerando-se apenas os 88 casos positivos por ambos ou sòmente por um dos métodos, os resultados foram concordantes em $45(59,8 \%)$.

É de se notar que embora o processo clássico de isolamento do $C$. diphtheriae tenha sido positivo em 25 casos (18,9\%) negativos pela prova de hemaglutinação passiva, esta, por sua vez, revelou $18 \mathrm{ca}$ sos positivos $(13,6 \%)$ para os quais a cultura foi negativa. Levando-se em consideração apenas os 88 casos positivos por ambas ou sòmente por uma das técnicas, a hemaglutinação passiva, ainda que negativa em $28,4 \%$, foi a única a evidenciar a considerável proporção de $20,5 \%$.

Os 63 casos positivos pela hemaglutinação passiva revelaram títulos que variaram de 2 a 256 e cuja distribuição foi a seguinte: 23 casos $(36,5 \%)$ com título 2 , $16(25,4 \%)$ com título $4,8(12,7 \%)$ com título $8,8(12,7 \%)$ com $16,2(3,2 \%)$ com $32,2(3,2 \%)$ com $64,1(1,6 \%)$ com 128 e $3(4,8 \%)$ com título 256 . Os 3 casos com êste título foram todos negativos pela cultura.

b) Casos clinicos de amigdalite aguda não diftérica - Dos 16 casos clínicos de amigdalite aguda, $4(25,0 \%)$ foram positivos pela hemaglutinação passiva e 2 $(12,5 \%)$, pela cultura.

Considerando-se os casos positivos evidenciados sòmente por uma ou pela outra técnica ou por ambas, encontram-se 5 $(31,3 \%)$. Ambos os processos revelaram resultado positivo em 2 casos $(12,5 \%)$ e resultado negativo em $11(68,8 \%)$, sendo a taxa de concordância de $81,3 \%$.

A cultura evidenciou 1 caso positivo não revelado pela hemaglutinação passiva e esta prova foi positiva em 2 casos negativos pela cultura.

Dos 4 casos positivos pela hemaglutinação passiva, um o foi com título 2 , um com, 4 , um com 8 e um com 16 .

Total de casos - Considerando-se todos os 148 casos estudados, encontraram-se 67 $(45,3 \%)$ positivos pela hemaglutinação passiva e $72(48,6 \%)$ positivos pela cultura. 
Christovao, D. de A.; COTillo Z., L. G. \& CANDeias, J. A. N. - Prova de hemaglutinação passiva para a evidenciação da. Rev. Saúde públ., S. Paulo 1(2): 210-216, dez. 1967.

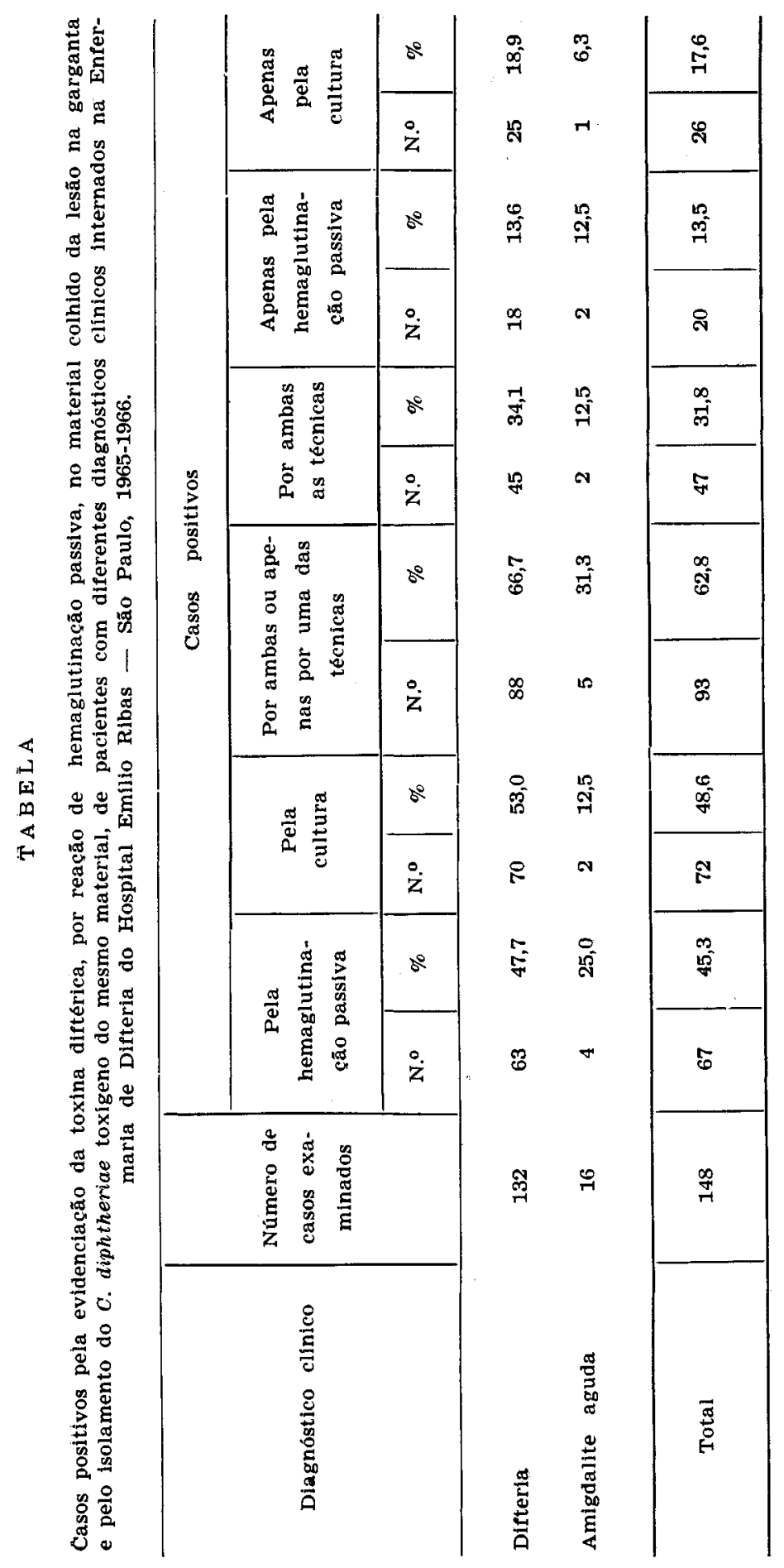


CHRistovao, D. de A.; COTILlo z., L. G. \& CANDEIAS, J. A. N. - Prova de hemaglutinação passiva para a evidenciação da.. Rev. Saúde públ., S. Paulo 1(2): 210-216, dez. 1967.

Dos $93(62,8 \%)$ casos positivos por ambas as técnicas ou sòmente por uma delas, os positivos pela hemaglutinação passiva representam $72,0 \%$ e os evidenciados pela cultura, $77,4 \%$.

Ambos os processos concordaram em 47 casos positivos $(31,8 \%)$ e em 55 negativos $(37,2 \%)$, verificando-se uma taxa de concordância de $68,9 \%$. Se forem tomados apenas os 92 casos positivos por ambas ou apenas por uma das técnicas, a taxa de concordância baixa para $50,5 \%$.

No total, o método da cultura foi o único a acusar resultado positivo em 26 casos $(17,6 \%)$ e a prova de hemaglutinação passiva foi a única positiva em 20 casos $(13,5 \%)$. Tomando-se apenas os 93 casos positivos por ambos ou sòmente por um dos métodos, a hemaglutinação passiva, negativa embora em $28,0 \%$, revelou $21,5 \%$ de casos não comprovados pelo isolamento do C. diphtheriae toxígeno.

Do total de 67 casos positivos pela prova de hemaglutinação passiva, 24 $(35,8 \%)$ o foram ùnicamente no título 2 e $43(64,2 \%)$ apresentaram títulos de 4 a 256.

Além dêstes 148 pacientes, foram estudados mais 5 casos com diagnóstico clínico de difteria para os quais a prova de hemaglutinação passiva foi negativa e a cultura revelou a presença de $C$. diphtheriae atoxígeno e mais 2 casos com diagnóstico clínico de monilíase dos quais um foi positivo por ambas as técnicas, sendo de 128 o seu título de hemaglutinação passiva.

\section{DISCUSSA}

Através da prova de hemaglutinação passiva descrita por Christovẫo \& CoTILLo $^{3}$ (1966) e na qual se utilizam hemácias às quais foi adsorvida antitoxina diftérica, foi possível evidenciar-se a presença da toxina do $C$. diphtheriae na lesão da garganta de $47,7 \%$ dos casos suspeitos de difteria examinados nesta investigação. $\mathbf{O}$ processo clássico da cultura para isolamento do bacilo diftérico, toma- do como base de julgamento da eficiência da nova técnica, foi capaz de comprovar porcentagem $(53,0 \% \%)$ algo superior. Tanto um como o outro método, se pudessem ser considerados como de difteria todos os casos clìnicamente diagnosticados como tal, teriam sido capazes de revelar apenas cêrca da metade.

São conhecidas, entretanto, a dificuldade que se apresenta muitas vêzes no estabelecimento do diagnóstico clínico desta infecção e a possibilidade de engano daí decorrente. Considerando-se como realmente de difteria apenas os casos evidenciados pelo menos por uma das técnicas utilizadas, poder-se-ia concluir que a prova de hemaglutinação passiva teria revelado $71,6 \%$ e a tentativa de isolamento, $79,5 \%$. Ainda assim, a eficiência do processo clássico teria sido $11,0 \%$ maior.

No entanto, tendo ocorrido substancial discordância entre os resultados de ambos os métodos e havendo a prova de hemaglutinação passiva sido a única positiva em $13,6 \%$ dos casos clìnicamente diagnosticados como de difteria ou em $20,5 \%$ dos casos positivos através de pelo menos uma das técnicas experimentadas, pareceria justificado o emprêgo de ambos os processos.

Em locais como São Paulo (ChristoVÃo ${ }^{1}, 1957$ ) onde a incidência de cepas de $C$. diphtheriae fermentadoras de sacarose é extraordinàriamente elevada, $o$ isolamento e identificação do bacilo diftérico é processo longo que pode demorar até 6 e mesmo 7 dias, dada a indispensabilidade da realização de provas de toxigenicidade sempre que a cepa isolada, ao lado de característicos do $C$. diphtheriae, apresenta a propriedade de atacar aquêle açúcar. Pelo menos nestas circunstâncias, se não sempre, a pesquisa da toxina diftérica, além daquela do $C$. diphtheriae, representaria sobrecarga de trabalho muito pequena. E uma vez que o resultado da pesquisa da toxina na lesão, pelo método experimentado, pode ser conhecido em menos de 2 horas após a colheita do material, a vantagem do processo pareceria indubitável. 
Christovao, D. de A.; Cotillo z., L. G. \& CANDEIAS, J. A. N. - Prova de hemaglutinaçăo passiva para a evidenciação da. Rev. Saúde públ., S. Paulo 1(2): 210-216, dez. 1967.

A rapidez do método, além disso, sempre que o caso fôsse precoce e benigno, permitiria ao clínico aguardar o seu resultado. Sempre que positivo, forneceria justificação ampla para a aplicação de antitoxina.

Seria necessário, entretanto, poder ter-se a certeza de que a prova de hemaglutinação passiva ora investigada é específica. 0 próprio fato dêste processo ter acusado resultados positivos em porcentagem considerável de casos não revelados pelo método clássico da cultura, anteriormente apontado como vantajoso, poderia servir de base para suspeitar-se da sua especificidade porquanto, na realidade, não se disporia, no momento, de razões para justificar tal proporção de falhas do isolamento do bacilo diftérico.

$A$ priori, esta prova náo deveria ser inespecífica, a menos que na gamaglobulina antidiftérica utilizada na reação, al. tamente purificada e concentrada, obtida a partir dos soros de cavalos hiperimunizados com toxóide e toxina diftéricos, pudessem existir outros anticorpos em quantidade suficiente para reagir com antígenos eventualmente presentes no material examinado. Assim, por exemplo, poderse-ia lembrar a possibilidade dos cavalos imunizados apresentarem anticorpos contra estafilicocos ou contra estreptococos, bactérias tão freqüentemente encontradas na orofaringe humana.

Entretanto, os resultados todos negativos encontrados nas 42 crianças com amigdalite ou amigdalite e faringite ocasionadas pelos germes acima referidos, sugeririam a especificidade do método.

Sòmente estudos posteriores englobando número bem maior de casos poderiam fornecer elementos suficientes para o julgamento da verdadeira eficiência da técnica ora investigada. A propósito, em trabalho anterior (Christovão \& CotILLo $\left.^{s}, 1966\right)$, já foi delineada investigação mais completa sôbre a questão. Tal in- vestigação terá de se basear no estudo de casos clínicos mais rigorosamente selecionados e com antecedentes terapêuticos perfeitamente conhecidos, o que nem sempre foi conseguido nos casos ora estudados Éstes cuidados são necessários a fim de se poder afastar completamente a possibilidade da medicação por antibióticos ou pela própria antitoxina diftérica, anterior à colheita do material, interferir nos resultados do isolamento do bacilo diftérico ou da evidenciação da sua toxina

\section{CONCLUSOES}

1. E possivel evidenciar-se a toxina do C. diphtheriae na lesão da garganta através de prova de hemaglutinação passiva, empregando-se hemácias sen. sibilizadas com antitoxina diftérica.

2. O processo, de execução muito simples, pode acusar o resultado em menos de 2 horas.

3. Tal método oferece grande possibilidade de aplicação vantajosa no diag. nóstico da difteria.

\section{S U M M A R Y}

The presense of $C$. diphtheriae toxin was demonstrated in throat lesions of 47.7 per cent of case 'with probable diagnosis of diphtheria, by passive hemagglutination test using erithrocytes previously sensitized by diphtheria anti-toxin. From 53.0 per cent of the same patients toxigenous bacilli were isolated. Hemagglutination test was the only positive one in 13.6 per cent of cases and cultivation in 18.9 per cent. The passive hemagglutination tests performed on 42 children, normal or with pharyngitis or tonsillitis but without clinical characteristics of diphtheria were all negative. The procedure described in this paper, of very simple execution can show results in less than two hours and offers great possibility of advantageous application in the diagnosis of diphtheria. 
Christovão, D. de A.; COTILlo z., L. G. \& CANDEIAS, J. A. N. - Prova de hemaglutinação passiva para a evidenciação da.. Rev. Saúde públ, S. Paulo 1(2): 210-216, dez. 1967.

\section{REFERENCIAS BIBLIOGRAFICAS}

1. CHRISTOVAO, D. de A. - Estudo sôbre o Corynebacterium diphtheriae. I. Fermentação da sacarose por bacilos diftéricos virulentos isolados em São Paulo. Arq. Fac. Hig. S. Paulo, 11 (1) :97-114, jun. 1957.

2. Estudo sôbre o Corynebacterium diphtheriae. II. Observações sôbre bacilos diftéricos e difteróides isolados em São Paulo: aspecto morfológico, propriedades fermentativas, virulências e freqüência dos tipos de Corynebacterium diphtheriae encontrados. Arq. Fac. Hig. S. Paulo, 11(1): 115-134, jun. 1957.
3. Christovao, D. A. \& COTILlo z., L. G. Pesquisa de Josagem da toxina diftérica no sangue de pacientes de difteria por reaçāo de hemaglutinação passiva. Arq. Fac. Hig. S. Paulo, 20(2):223232, dez. 1966.

4. FROBISHER, M. et alij - "Diphtheria" In: AMERICAN Public Health Association. Diagnostic procedures and reagents. 4th ed., New York, 1963. p 231260.

5. TASMAN, A. et alii - The presence of diphtheria toxin in the saliva of diphtheria patients. The pathogenesis of diphtheria. Ned. T. Geneesk, 98:3388-3398, Nov. 1954. Res. in $E x$ cerpta med., Seci. IV. Amsterdan, 8 (11) :682, Nov. 1955 . 